\title{
基于应用型人才培养的高校开放式实验室建设
}

\section{Open Laboratory Construction in Colleges and Universities Based on the Cultivation of Applied Talents}

吴波

Bo Wu

太原理工大学现代科技学院

中国・山西 太原 030002

School of Modern Science and Technology,

Taiyuan University of Technology,

Taiyuan, Shanxi, 030002, China
【摘要】近年来,社会对应用型人才的需求越来越大。在这种情况下, 高校自身的教育改 革和建设被提上日程。所以, 高校进行了开放式实验室的建设, 来提高学生的实践水平, 实 现应用型人才的培养目标。论文从开放式实验室在硬件上和软件上的需求以及开放式实 验室运行模式和具体的实行措施出发, 阐述正确建设开放式实验室的方法。

【Abstract】In recent years, society has become more and more demanding for applied talents. In this case, the education reform and construction of the university itself is put on the agenda. Therefore, colleges and universities have carried out the construction of open laboratories to improve the students' practical level and achieve the training objectives of applied talents. This paper starts from the open laboratory's hardware and software requirements, as well as the open laboratory operation mode and specific implementation measures, explains how to correctly build an open laboratory.

【关键词】应用型人才; 高校; 开放式实验室

【Keywords \applied talents; colleges and universities; open laboratory

【DOI】10.36012/sde.v2i1.820

\section{1 引言}

近年来, 社会各界对人才的要求已经不仅仅体现在分数 和理论知识上, 而是要得到既高分又高能的全能人才。在这种 形式下, 如何培养学生的实践动手能力, 培养出知行合一, 也 就是理论和实践相结合的完美的学生成了一件非常重要的 事, 甚至成为一个学生乃至整个专业生死存亡的大事。所以, 社会上的众多高校都开始想办法如何来提高学生的动手能 力。而培养开放式实验室来增强学生的动手实践能力, 进而培 养出应用型人才, 成为当下最有效的一种手段。开放式实验室 是一种能以较低的成本综合地提高学生们的创新能力、动手 能力以及提升教师的教学效果的实验室, 其低成本、高收益的 优势使其得以在高校改革中成为一颗不可忽视的新星。所以,
建设开放式实验室成为了高校进行教学改革、培养应用型人 才的必然,而基于应用型人才培养的开放式实验室建设,正是 人们需要考虑的。

\section{2 开放式实验室在硬件上的建设}

基于应用型人才的开放式实验室在硬件上的主要要求 是: 增加对实验室的定义和规范, 同时加强实验设备的建设。 因为实验室是学生学习练习的场所, 所以假如空间不足的话, 则无法满足应用型人才的需求。具体表现在实验的某些规范 化标准要求都无法达到, 所以实验室的人均面积应该定为至 少每人五平米的空间范围 ${ }^{[1]}$ 。不仅如此, 建设开放式实验室本 质上是为了学生们进行理论验证实践动手的地方, 所以对设 备的性能也有要求。然而在实际中,基本的设备是否齐全的问 
教育管理 Education Management

题还有待完善。针对这种情况,开放式实验室在硬件方面的建 设必须加大投资来改善设备条件,采用较为先进的实验设施, 这样才能满足应用型人才的需求。

\section{3 开放式实验室在软件上的建设}

第一，每一个新项目的初步建成后，都需要制订一个规 范, 毕竟“没有规矩不成方圆”。同样, 没有一个规范, 实验室 的管理势必会出问题, 从而最终导致整个项目的失败。所以, 在初步建成开放式实验室之后, 首先要做的就是立法, 在法律 的角度，规范化使用开放式实验室。例如，可以根据实际情 况，建立一些基本的设备借用条例和使用实验室的安全行为 规范, 并且必须针对现实情况, 随时修改制度, 逐步完善 ${ }^{[2]}$ 。只 要这样,才能对开放式实验室在法律上形成保护, 以此来维护 应用型人才的合法权益。

第二, 实验室必须要配备专业化的指导教师, 并且要常驻 实验室来对学生随时进行指导, 最好每个实验室都能至少有 一名这种指导教师，也要对指导教师的实践能力进行一个强 化培养，甚至能让这些指导教师开始慢慢走向职业实验师的 职称序列, 这样才能使教师队伍都能有正确的职称, 促进职称 的合理化需求。

第三,针对不同的专业学生,也应尽早制订不同的实验教 材。只有系统化的教材指导, 才能正确地对各专业的学生进行 专业化的培养, 才能培养出适合的应用型人才, 同时也提高学 生的学习效率。在学生做完实验后, 也可以让他们随时填写实 验后的报告单, 这样有利于教师实时了解学生在开放式实验 室的收获, 对学生进行专业化的指导。

\section{4 开放式实验室的运行模式}

开放式实验室的管理，应该在保证不耽误专业课程的前 提下,在学生们的课余时间进行开放。还可以采用提前预约等 模式, 这样就可以把实验人数、实验内容和实验时间提前公布 出来。学生们就可以根据公布出来的内容调整自己的时间, 同 时也提高学生学习知识的自主性等, 并且尽可能地让所有的
学生都参与进来, 而不是只是部分学生的学习圣地, 其他学生 永不踏入的禁地。不仅如此,专业课程的老师也应该在专业课 上多下功夫，想办法把专业课程和实验结合起来。在课程设 计、毕业设计、竞赛活动方面都可以完美地发挥实验室的功 效, 让学生们把开放式实验室变成经常去的地方, 也让实验室 给学生们提供一个学习的天堂。在实验室中, 因为具备了较为 先进的实验设施, 再加上学科专业本身就负担了大量的科研 工作, 而这些工作也可以分担给学生, 学生通过参与科研工 作, 来提升自身的创新能力, 同时也提高了自身的学习兴趣和 成就感 ${ }^{[3]}$

\section{5 开放式实验室的具体实行措施}

建设好开放式实验室之后, 还要把参与实验室实验和学 分挂钩, 这样才能提高学生参与实验的积极性和主观性, 即对 于参与实验室实验的学生, 增设一个实践素质教育学分, 同时 规定毕业生在实践素质教育学分中必须要有个最低的实验分 数。除此之外, 应对实验室教师的待遇适当地进行一些改善, 毕竟要保证开放式实验室的正常运作, 就得让实验室教师投 人大量的时间和精力。同时也要注意对于实验室规章制度的 完善, 力求尽早建立良好的监督程序, 这对于设备的使用维护 以及实验室的正常运行至关重要。

\section{6 结语}

培养应用型人才离不开开放式实验室。各大高校陆续建 设开放式实验室, 势必会缓解社会对于应用型人才的需求, 为 社会做出巨大的贡献。

\section{参考文献}

[1]王科飞.基于应用型人才培养的高校开放式实验室建设 [J].长 春金融高等专科学校学报,2010(2):70-72.

[2]蔡晚拴.加快开放实验室建设 促进应用型人才培养[J].实验室 科学,2016,19(4):174-177.

[3]舒惠霞.浅谈高校实验室基于应用型人才培养的建设 [J].科技 信息,2010(29):195. 